\title{
O Diabo na arte e no imaginário ocidental
}

\author{
Antonio Carlos de Melo Magalhães \\ Eli Brandão
}

MAGALHÃES, ACM., and BRANDÃO, E. O Diabo na arte e no imaginário ocidental. In

MAGALHÃES, ACM., et al., orgs. O demoníaco na literatura [online]. Campina Grande: EDUEPB, 2012. pp. 277-290. ISBN 978-85-7879-188-9. Available from SciELO Books

<http://books.scielo.org>.

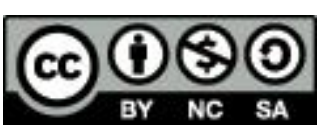

All the contents of this work, except where otherwise noted, is licensed under a Creative Commons Attribution-Non Commercial-ShareAlike 3.0 Unported.

Todo o conteúdo deste trabalho, exceto quando houver ressalva, é publicado sob a licença Creative Commons Atribuição Uso Não Comercial - Partilha nos Mesmos Termos 3.0 Não adaptada.

Todo el contenido de esta obra, excepto donde se indique lo contrario, está bajo licencia de la licencia Creative Commons Reconocimento-NoComercial-CompartirIgual 3.0 Unported. 


\title{
O Diabo na arte e no imaginário ocidental.
}

\author{
Antonio Carlos de Melo Magalhães ${ }^{1}$ \\ Eli Brandão ${ }^{2}$
}

\section{Introdução}

É possível identificar o desenvolvimento, as oscilações e as continuidades nas representações e crenças no diabo no âmbito da arte, da religião e das ideologias. Ainda que existam identidades epocais, que sedimentam a longa história humana, não podemos deixar de reconhecer matizes, especificidades na história do diabo no imaginário ocidental.

\section{Curta história do Diabo}

Indubitavelmente, a primeira grande sistematização e unificação foi elaborada pelos teólogos medievais dos séculos XII e XIII, resultado da ascensão do cristianismo à religião do Império, mas que encontrou sua grande sistematização justamente nos séculos mencionados, em seguida encontrou força especial nos séculos XIV a XVI nas mãos dos artistas renascentistas, saiu um tanto combalido da luta que enfrentou com o Iluminismo europeu nos séculos XVII e XVIII, foi redescoberto como mito literário de forma especial pelos autores românticos dos séculos

1 Doutor pela Universidade de Hamburg, Alemanha. Professor do Departamento de Filosofia e Docente Permanente do Programa de Pós-Graduação em Literatura e Interculturalidade da Universidade Estadual da Paraíba.

2 Doutor pela UMESP - São Paulo. Professor do Departamento de Letras e Docente Permanente do Programa de Pós-Graduação em Literatura e Interculturalidade da Universidade Estadual da Paraíba. 
XVII a XIX e não saiu incólume da indústria cultural do século XX, voltada para a transformação dos bens simbólicos em mercadorias sedutoras aos gostos do consumidor.

Claro, não estamos dizendo com esta visão panorâmica, baseada mais nas grandes representações de cada período, que o Diabo não existia antes nos imaginários e nas narrativas. As religiões monoteístas não deixam isto em dúvida. O Diabo faz parte dos imaginários religiosos, mas nossa hipótese de trabalho é que ele nunca foi assim tão importante como figura, pessoa, representação e força do imaginário como na Idade Média e depois no renascimento. Mesmo na Baixa Idade Média, por exemplo, Agostinho não recorre tanto à existência do diabo para explicar a queda, mas ao problema do mal. Quero dizer, ele não se apressa em personificar o mal, mas em compreendê-lo como parte do dilema da vida humana. Mesmo no Novo Testamento - com certeza responsável por boa parte das imagens que temos acerca do diabo -, ele é mais forte na literatura escatológica (alguns textos dos Evangelhos) e apocalíptica (Apocalipse de João), tendo somente relativa ou insignificante influência em outros livros.

No Primeiro Testamento/na Bíblia Hebraica sua participação é mais pedagógica que necessariamente um anti-Deus ou uma força em contraposição a Deus. Não há dúvida, porém, que o Diabo é quase sem importância para o conjunto de textos do Primeiro Testamento/da Bíblia Hebraica. E quando associações a esta imagem surgem, há uma dimensão de complementação ao divino, ao núcleo do sagrado.

O Diabo passou, portanto, por várias representações, tendo uma face terrível, mas muitas vezes apresentado com muita ironia, quase como um bufão da corte, e, outras vezes, como figura necessária à ordem do mundo. Então é sempre bom explicar de que Diabo estamos falando. De qualquer forma, ele é figura insuperável como mito religioso, como convicção religiosa mais conservadora, como parte do imaginário ocidental e constitutivo da arte no ocidente e no oriente.

Uma coisa é certa: o cristianismo é o principal responsável pela força do Diabo no mundo, pois é justamente nele que as representações e projeções do Diabo encontrarão um singular avanço na cultura e na civilização. 


\section{Arte, cultura popular e representações do Diabo}

Um longo caminho é percorrido para se chegar a grandes representações do Diabo na arte. O que a pesquisa especializada nos indica é que isto se deu especialmente a partir da força de algumas representações na cultura popular fortemente religiosa. Sim, porque nas primeiras grandes representações do teatro (grego e romano) o Diabo não tinha papel no palco nem nas letras. É dentro da cultura popular cristã e pagã que o Diabo passará a ter força na arte.

Numa grande circulação de bens simbólicos, o Diabo era uma entre tantas outras ofertas e a pesquisa deveria considerar este papel ainda subalterno para depois entender melhor o papel quase hegemônico que passou a ter.

Até o século XII o mundo era demasiado encantado para permitir a Lúcifer ocupar todo espaço do medo, do temor ou da angústia. O pobre diabo tinha concorrentes demais para reinar absoluto, ainda mais porque o teatro do século XII fazia dele uma imagem de paródia ou francamente cômica, retomando o veio popular referente ao Mal ludibriado. (MUCHEMBLED: 2001, p. 31)

E aí há vários aspectos a serem considerados, sumariamente apresentados por Russel.

A ligação mais íntima entre o Diabo da arte e o Diabo da literatura é o demônio do teatro. A elaborada literatura de visão do inferno influenciou as artes de representação tanto quanto Dante, e algumas pinturas são virtualmente ilustrações de tais visões. Arte e teatro influenciam-se pelo menos no fim do século XII, quando o teatro vernáculo começou a ser popular. A representação do Diabo no teatro foi derivada de impressões visuais e literárias, e em troca artistas que tinham visto produções de teatro modificaram a própria visão deles. $\mathrm{O}$ pequeno e preto diabinho que não pôde ser representado facilmente no teatro declinou no final da Idade Média. O desejo de impressionar as audiências com 
fantasias grotescas pode ter encorajado o desenvolvimento do grotesco na arte, fantasias de animais com chifres, rabos, presa, casco rachado e asas; fantasias de monstro, meio-animal e meio-humano; e fantasias com faces nas nádegas, barriga ou joelhos. Máscaras, luvas com garras e dispositivos para projetar fumaça pela face do demônio também eram usados. (RUSSEL: 2003, p. 245-6)

É justamente neste período de várias intersecções entre arte, cultura popular e religião, que a teologia e a instituição eclesiástica fortalecem a preocupação em sistematizar sua visão da ação do Diabo no mundo. Mais até: procuram mostrar a gravidade de um mundo dirigido pela força demoníaca.

Pode-se datar do fim do século XII, o momento em que, devido sobretudo à acentuação das ameaças heréticas, se passa de um estado de relativo equilíbrio na matéria a uma acentuada preocupação pela ação diabólica. A amplitude das ameaças com que se acha confrontada a Igreja, com os Bogomilos, os Valdenses e os Cátaros, sem esquecer a pressão turca e a presença dos judeus, explica em parte a atenção obsessiva que é dada ao Diabo. Como muito bem viu Jean Delumeau, instala-se na cristandade um medo difuso que ajuda a criar a idéia de que está em curso um ataque concentrado contra o cristianismo, um ataque conduzido por uma potência sobrenatural pelo inimigo, o Diabo. (MINOIS: 2003, p. 68)

Aqui não podemos deixar de perceber uma relação bastante ambígua da arte. Por um lado, ela captou bem as formas diversas da cultura popular lidar com as representações do Diabo, por outro, ela também serviu aos interesses sistematizadores da Igreja de tornar estas representações ainda mais fortes para o uso despótico da instituição numa verdadeira pedagogia do medo. Claro, até que ponto isto foi obra dos artistas ou mero uso institucional é algo que mereceria uma pesquisa à parte. De qualquer forma, é importante anotar esta ambigüidade presente na relação da arte com as representações do Diabo e seus usos institucionais. A mesma ambigüidade, talvez até de forma mais acentuada, encontramos no Renascimento. 
Outro capítulo importante é considerar o papel que o Iluminismo teve no processo de racionalização e desencantamento do mundo. Isto significou a emergência de grupos sociais cada vez mais preocupados em interpretar o mundo e seus fenômenos a partir de categorias racionais e não a partir de uma tutela do sobrenatural sobre o natural. É assim que vamos encontrar mudanças no discurso sobre o diabo e que ele entrará em declínio nos grandes sistemas teológicos e na arte sob a tutela da religião.

Entre o século XVI e o século XVIII, o discurso sobre o Diabo passa por uma mutação radical. Deixa de ser uma obsessão religiosa e, no período imediatamente anterior ao romantismo, transformase num grande mito literário. A substituição de Satanás por Mefistófeles não é fundamentalmente um processo de natureza religiosa, mas de natureza simbólica. Não se trata, portanto, de uma passagem da crença à descrença, mas uma transição entre mitos. O Diabo, com efeito, laiciza-se, o seu papel perpetua-se, mas com inversão de sinal. (MINOIS: 2003, p. 110)

A literatura romântica representou um momento forte da literatura em sua reescritura sobre o Diabo, propondo uma inversão na forma como o Diabo era interpretado. Por outro lado, não deixa de apresentar um diálogo com dimensões pedagógicas que a figura do Diabo tinha na Bíblia Hebraica. E fez isto ainda sob o impacto do Iluminismo.

O Romantismo transformará Satã no símbolo do espírito livre, da vida alegre, não contra uma lei moral, mas segundo uma lei natural, contrária à aversão por este mundo pregada pela Igreja. Satanás significa liberdade, progresso, ciência, vida. Tornar-se-á moda a identificação com o Demônio, assim como procurar refletir no semblante o olhar, o riso, a zombaria impressos nas feições tradicionais do Diabo. (...) O Diabo passa a representar a rebelião contra a fé e a moral tradicional, representando a revolta do homem, mas com a aceitação do sofrimento porque este é uma fonte purificadora 
do espírito, uma nobreza moral, da qual só pode surgir o bem da humanidade. E o demoníaco tornase o símbolo do Renascimento: demoníaco como paixão, como terror do desconhecido, como descoberta do lado irracional existente no homem: a explosão da imaginação contra obstáculos excessivos da consciência e das leis. (NOGUEIRA: 2000, p. 104-5)

Partimos do princípio que o uso que o romantismo faz do Diabo está dentro de uma tradição da arte já indicada neste texto, mas também representa um passo importante para a compreensão do Diabo como mito literário, criando um fosso entre a visão que se tem majoritariamente na religião e a visão que se tem na arte. Cada vez mais, após o romantismo, o Diabo perde espaço na literatura ou apropria-se de suas características para construir personagens complexos. O que era coisa do diabo passa a ser cada vez mais coisa do humano. Nas obras de escritores como Goethe (1749), Willian Blake (1757-1827), Balzac (1799-1850), Victor Hugo (1821-1867), além de Dostoiévski (1821-1881) entre outros, e Baudelaire (1821-1867) considerados ou românticos ou elos entre o romantismo e o modernismo, o imaginário literário significou um forte abalo do exclusivismo teológico. É o Diabo plenamente no mundo onírico, grotesco e fantástico, mas também com indicações importantes de que ele seria rapidamente relativizado dentro deste mundo.

Ao final do século XIX, o Diabo mostrava sinais evidentes de envelhecimento, primeiro porque sua existência fisica vinha sendo amplamente desacreditada, e depois porque sua função como metáfora do mal era considerada por muitos como ultrapassada. Assim, no início do século XX, novas e mais abstratas explicações filosóficas e políticas para os infortúnios mundanos já ocupavam um espaço muito mais amplo. Entretanto, mesmo relegado ao esquecimento, o Diabo continuou exercendo seu fascínio natural, pois embora os poetas, os artistas e os escritores o tivessem posto de lado em favor de outras soluções para os eternos dilemas da 
humanidade, a psique popular nunca deixou de tê-lo como bode expiatório, sobretudo nos tempos mais dificeis. (STANFORD: 2003, p. 279-80)

Com isto temos um processo crescente de interiorização do mal na literatura. Cada vez mais o que era atribuído ao Diabo, é um problema nosso ou da sociedade. O homem-humano, assim como indicado em textos de Guimarães Rosa, é a grande personificação do mal. A insatisfação e a ambigüidade da condição humana passam a ser cada vez mais motivos literários. É o natural que importa, não mais o sobrenatural.

\section{Literariedade e ambiguidades da figura do Diabo}

Partimos do pressuposto de que fenômeno da religião se manifesta na cultura de todas as civilizações conhecidas e que a literatura é, por excelência, escritora e reescritora dos discursos teológicos que forjam o imaginário ocidental, no qual, como temos argumentado, o Diabo aparece como uma figura central das tradições cristãs. Entretanto, pelo fato dessas referidas tradições serem construídas ao longo de um processo histórico no qual a ambiguidade humana é determinante e em meio a uma diversidade cultural, a figura do Diabo, consequentemente, mesmo dentro de um mesmo contexto [como se dissesse: "Meu nome é legião, porque somos muitos"] apresenta ambiguidades, numa riqueza polissêmica que transita entre o sério e o cômico, o espanto e a admiração, o belo e o grotesco, o oficial e o popular, o sacro e o profano, o bem e o mal, exemplarmente.

Ao entendermos a literatura como escritora e reescritora dos discursos da religião, queremos ressaltar o caráter literário das narrativas míticas em geral e, em particular, dos textos que formam a tradição judaico-cristã, afirmando que o mito somente se configura na superfície linguística como literatura, que a Bíblia, portanto, é Literatura. Neste sentido, e a partir da compreensão de que a literatura se constrói como intérprete das vivências pessoais e socioculturais do humano, como intérprete de textos verbais e não-verbais, orais e escritos, podemos dizer que a figura do Diabo apenas surge na escrita por meio da expressão literária. Assim, a literatura continua a criar e recriar, refletir e refratar os diversos percursos temáticos e figurativos do Diabo, evidenciando o seu caráter 
palimpsêstico e pluridiscursivo, possibilitando que se estabeleça em seu interior um produtivo diálogo entre diversos discursos, onde vozes teológicas falam e polemizam com outras e entre si.

Ao selecionarmos a dimensão literária para refletirmos sobre a figura do Diabo, não pretendemos reduzir a abordagem à moda dos formalistas russos, mas buscamos seguir a concepção de texto, no sentido de Greimas \& Courtès, como unidade da manifestação, o lugar onde um plano de conteúdo é manifestado por meio de um plano de expressão. A unidade do plano de conteúdo é o discurso, patamar do percurso gerativo de sentido em que as estruturas narrativas são assumidas por um enunciador, actorializadas, especializadas, temporalizadas e revestidas de temas e/ou figuras (apud FIORIN, 1994, p. 30-31). Neste sentido, o texto não pode ser considerado como algo em si, pois, por um lado, ele é um sistema concluído, um conjunto hierarquizado de configurações estruturais internas; por outro, é o lugar onde se manifestam e se expressam relações entre textos e textos, entre textos e pessoas, entre textos e realidades socioculturais, ou seja, texto aqui entendido como um objeto aberto, plural, dialógico, ligado ao contexto extraverbal.

A partir disso, entendemos que as figuras do Diabo presentes nos diversos textos literários estão em permanente diálogo interdiscursivo com outros textos, em relação aos quais definem suas identidades e/ou diferenças (MAINGUENEAU, 1997), num processo de reconfiguração incessante, incorporando elementos pré-construídos e/ou provocando sua redefinição.

A literatura, como já vimos, por meio de sua criação e representação, tem mostrado, ao longo da história, uma riqueza em exemplos de figuras do Diabo e, mais abundantemente, de figuras do Diabo horripilante e maléfico, em oposição ao Deus do bem, este relacionado à virtude pelo discurso teológico oficial das igrejas cristãs, mas também figuras de um Diabo mais bondoso, cômico e integrado à divindade.

Selecionamos aqui, exemplos de figura do Diabo na literatura através do qual podemos vislumbrar no interdiscurso semelhanças e diferenças, bem como sutilidades teológicas que trazem à tona contradições internas ao discurso da igreja cristã, expressivas também das ambiguidades e interpretações dos fiéis em sua vivência cristã. 
Proust (1994, p.103), em A propósito de Baudelaire, já ressaltava como o poeta dAs Flores do Mal, no poema "As Litanias de Satã", refletia e ao mesmo tempo refratava conceitos da tradição teológica cristã, ao sugerir que beleza, majestade, esperança, o Deus, a quem se dirige a oração do aflito e "o cuidado de ensinar a mais profunda teologia está confiado a Satã”.

Ó tu, o Anjo mais belo e o mais sábio Senhor,

Deus que a sorte traiu e privou de louvor, Tem piedade, Satã, desta longa miséria! (...)

Tu, sábio e grande rei do abismo mais profundo, Médico familiar dos males deste mundo, Tem piedade, Satã, desta longa miséria!

(...)

Ó tu, o que da Morte, a tua velha amante, Engendraste a Esperança - a louca fascinante!

Tem piedade, Satã, desta longa miséria!

E prossegue o poeta Baudelaire, apontando relações sutis de polêmica com os discursos da teologia da igreja cristã, mas, ao mesmo tempo, em sintonia com possível hermenêutica do texto do Livro de Gênesis.

\section{ORAÇÃO}

Glória e louvor a ti, Satã, nas amplidões

Do céu, em que reinaste, e nas escuridões

Do inferno, em que vencido, sonhas com prudência! Deixa que eu, junto a ti, sob a Árvore da Ciência, Repouse, na hora em que, sobre a fronte, hás de ver Seus ramos como um Templo novo se estender!

Reflitamos agora em torno de uma obra na qual o Diabo é refigurado, neste caso, como personagens divinas multifacetárias, num interdiscurso que refletem e refratam figuras da tradição cristã. Selecionamos para este fim uma prosa da literatura brasileira, o Romance d'A Pedra do Reino e o príncipe do sangue do vai-e-volta, de Ariano Suassuna.

O Romance da Pedra do Reino é a auto-descrição do híbrido reino de Quaderna, uma bricolagem carnavalizante do mundo ibérico, através 
de sua literatura medieval e da tradição teológica da igreja cristã de vertente católica, tecida no contexto da cultura nordestina, numa ressignificação literária do movimento histórico-fantástico conhecido como "Pedra Bonita" ou "Pedra do Reino".

Quaderna, personagem principal e narrador, que, inspirado pela leitura do folheto da literatura de cordel, intitulado "O Estudante que se vendeu ao Diabo", de Lino Pedra-Verde, passa a andar com um espelho, depois do que teve uma visão, semelhante a que teve o estudante de Salamanca com o Diabo no cordel de Lino, através da qual ele viu refletido no espelho um vulto de uma Onça formada de pedras, mato estradas, sol... a qual foi the envolvendo e tragando para dentro de um buraco perigoso, oco e vazio. Depois dessa experiência, são recorrentes as aparições de entidades malignas multiformes que se opõem ao seu reino.

Em alguns momentos, por meio de uma refração interdiscursiva, esses personagens diabólicos e ameaçadores são identificados com forças políticas internacionais e intercontinentais, de direita e de esquerda, os quais são identificados por Quaderna, na forma indeterminada de "eles".

Eles era uma entidade maléfica que nunca consegui identificar precisamente, mas que, segundo parecia, era e é ligada à Besta Anglo-Saxã, à Besta-LouraCalibã - uma entidade que está em toda parte, inatingível, ameaçadora, invencível e diabólica. (SUASSUNA, p. 260).

Às vezes, o diabo é descrito dentro de um ambiente bem regional na forma animalesca de "cachorro", numa cena que ocorre no Chafariz perto do rio Taperoá, num depósito de lixo (SUASSUNA, 2006, p.328330). Em outra passagem, aparece também o diabo numa forma feminina: "uma diaba-fêmea do Mar e do Litoral, uma bicha horrorosa", também chamada de Bruzacã ou Hipupriapa ou Ipupiara. Ela tem aparência de peixe, mas peitos e cabeça de cachorro e orelhas num formato parecido com chifre. Para Quaderna, o mal da seca e da opressão é causado pela interferência desse Diabo, que "é o Mal, o Enigma, a Desordem!" (SUASSUNA, 2006, p.402). Trata-se de um demônio marinho e sertanejo, que passa seis meses no mar causando tempestades e devorando as Baleias. O mesmo Diabo, em setembro, sai do Mar, soprando fogo 
pelas ventas, causando a seca no sertão (SUASSUNA, 2006, p.403). Dependendo do período do ano e com a modalidade de aparição, marítima ou terrestre, esse Diabo feminino toma formas diferentes:

Ah, só quem já viu Bruzacã é que pode imaginar como são poderosas e aterrorizantes as formas que ela toma! São sete Chifres turvos e amolados, o Focinho peludo, a Corcova cerúlea! No cabelouro espesso, uma Cabeleira de serpentes e conchas entrançadas! O olhar de Cobra e o corpo feito à semelhança de um corpo enorme de Touro branco! Era a Besta marinha, partejada pelos lombos diabólicos e sagrados do Mar! Seu olhar chamejava, ora amarelo, ora azul como um aço de Martelo! Ao fogo do sopro das suas Ventas, ferviam as águas em borbulhas de Enxofre envenenado. O peito era coberto pelo musgo nojento que suja e mancha as paredes do Inferno alumiado! As espáduas eram cobertas de malhas feridentas cor de ferrugem e em cada uma das suas ancas verdes luzia uma estrela amarela, brilhando entre sargaços e salsugem, entre ostras pegadas ao tronco, anoso e velho como um velho Rochedo extraviado! (SUASSUNA, 2006, p.406)

Singular figuração do Diabo podemos observar no Reino de Quaderna, no que se refere à "Santíssima Trindade Sertaneja", que se apresenta com membros zoomórficos da fauna nordestina, num evidente interdiscurso tecido em diálogo polêmico e carnavalizante com a composição da santíssima trindade da teologia cristã católica.

O próprio Deus não era mais aquele sopro tênue das outras religiões: aparecia-me como a Santíssima Trindade Sertaneja, um Sol ardente e glorioso, formado por cinco animais num só. Era a Onça Malhada do Divino, integrada por cinco bichos: a Onça-Vermelha, a Onça-Negra, a Onça-Parda, a Corça Branca e o Gavião de Ouro, ou seja, o Pai, o Encourado, o Filho, a Compadecida e o Espírito Santo. (SUASSUNA, 2006, p.561). 
Para além da definição da composição da Santíssima Trindade Sertaneja, com cinco membros e com a inclusão do Diabo e da Compadecida, a oração invocatória não deixa dúvidas sobre a relação simbólica entre os animais e as pessoas da trindade:
Ó Onça-Vermelha do Pai! Ó Onça Negra do Encourado! Ó Onça Parda e Castanha do Filho! Ó Corça Branca! Ó Gavião de Ouro do Sol do Espírito Santo! (SUASSUNA, 2006, P. 558).

A Santíssima Trindade Sertaneja de Quaderna está profundamente relacionada a sua primeira experiência com o Diabo, por ocasião da visão que teve, e ao cenário do Nordeste brasileiro, de modo que é a Onça quem representa o conjunto da divindade:

Santíssima Trindade tem cinco, e é sempre figurada através do animal heráldico e armorial brasileiro por excelência, a Onça Malhada (SUASSUNA, 2006, p.551).

Pode parecer muito excêntrica a configuração da Santíssima Trindade Sertaneja de Quaderna, mas ela, interdiscursivamente, refrata mais a teologia oficial da igreja católica e menos a teologia do catolicismo popular, destacadamente aquele muito mais sincrético e livre do 'povão'. Isto porque, desde a Idade Média, quando o Diabo ganhou mais crédito, até os nossos dias, no contexto eclesiástico e fora dele, o Diabo sempre se apresentou como muito poderoso, com um poder divino que pode pôr à prova alguém que esteja sendo acusado de ser ou não ser cristão. Neste contexto, observamos que nos sermões dos padres e pastores há abundância de argumentação no intento de provar que o Diabo existe e que é poderoso. A prova de alguém ser ou não ser cristão não é, nesse caso, crer em Cristo, mas sim crer no Diabo, acreditar que ele existe e que é poderoso.

Por muito tempo ouvimos e ainda podemos ouvir hoje em corredores de discussão nas igrejas ou nos seminários de teologia, nas casas e nas ruas, a tese de que: quem não acredita na existência do Diabo não pode ser crente ou cristão. O Diabo é causa necessária do Deus cristão, Deus tem necessidade ontológica do Diabo, nessa compreensão. Assim, a configuração interdiscursiva da Trindade Sertaneja é não apenas criadora, 
mas também recriadora de determinados sentidos presentes na realidade da comunidade cristã. $O$ mesmo se pode dizer em relação à inclusão da Compadecida como membro da trindade sertaneja, visto que ela também se apresenta como divindade no catolicismo popular, em muitos contextos, com autoridade acima do Pai, do Filho e do espírito Santo.

Do que vimos, a figura do Diabo é histórica e teológica, polêmica e harmoniosa, sacra e profana, do bem e do mal, sendo sua semântica reconstruída por meio de um processo hermenêutico permanente a partir das vivências humanas, das expressões das artes em geral e dos textos verbais, de forma especial, da arte da palavra, a literatura, e do lugar discursivo do enunciador em seus diferentes contextos socioculturais, onde esse ser mitológico, essa figura do discurso e essa representação do vivido é de novo apropriada, refigurada, tecida, engendrando ressignificação dos sentidos possíveis para a existência humana. 


\section{Referências Bibliográficas}

BAUDELAIRE, Charles. As Flores do Mal. Trad., introd. e notas de Jamil Mansur Haddad. São Paulo: Difel, 1995.

FIORIN, José Luiz. Elementos de Análise do Discurso. São Paulo: Ed. Contexto, 1994.

MAINGUENEAU, Dominique. Novas tendências em análise do discurso. São Paulo/Campinas: Pontes/Editora UNICAMP, 1997.

MINOIS, G. O Diabo: origem e evolução histórica. Lisboa: Terramar, 2003

MUCHEMBLED, Robert. Uma história do diabo - séculos XII-XX. Tradução de Maria Helena Kühner. Rio de Janeiro: Bom Texto, 2001.

NOGUEIRA, C. R. F. O diabo no imaginário cristão. Bauru: Edusc, 2000.

Bruxaria e história: as práticas mágicas no ocidente cristão.

Bauru: Edusc, 2004.

PROUST, Marcel. A propósito de Baudelaire. in: Nas trilhas da crítica. Trad. Plínio Augusto Coelho. São Paulo: Edusp, 1994.

RUSSEL, Jeffrey Burton. O Lúcifer e o Diabo na Idade Média. São Paulo: Editora Madras, 2003.

STANFORD, P. O Diabo: uma biografia. Rio de Janeiro: Gryphus, 2003.

SUASSUnA, Ariano. Romance d'A Pedra do Reino e o príncipe do sangue do vai-e-volta. 8.ed. Rio de Janeiro: José Olympio, 2006. 




\section{LIVROS EDUEPB E LATUS}

1. Pluralismo Jurídico: Para além da visão monista - Raíssa de Lima e Melo

2. Mulher, corpo e cuidado - Maria de F. de A. Silveira; e Dulce M. Rosa Gualda

3. Avaliação de serviços: um olhar na qualidade da gestão - (Orgs) Maria José Cariri Benígna; e Maria A. Amado Rivera

4. Farmacêutico na Farmácia - Rosimary S. Cunha Lima; Maria do Carmo Eutálio; e Magnólia de L. S. Targino

5. Representações sociais e saúde - Aliana Fenandes; Maria. do R de Carvalho; e Moisés Domingos Sobrinho

6. EPI Info para iniciantes - (Orgs) Sonia Maria de L. Maciel; e Pedro Henrique de A. e S. Leite

7. Ensino de lingua: do impresso ao virtual - (Orgs) Antonio de Pádua Dias da Silva; Maria de L. L. Almeida; Simone Dália de Gusmão Aranha; e Tereza. N. de Farias Campina

8. A história da mídia regional - C. B de Souza; F. G. de Oliveira; e Gorete M. Sampaio de Freitas

9. Livro de resumo de monografias - Maria Dora Ruiz Temoche

10. Planejamento tributário no campo de incidência do ICMS - Alexandre H. S. Ferreira; e Ana Maria da P. Duarte

11. 1930 - A Revolução que mudou a História do Brasil - (Orgs) João M. L. Santos; Cláudo José L. Rodrigues; Inês Caminha L. Rodrigues; e José Octávio de A. Melo

12. Curso de Direito Constitucional - Lorivaldo da Conceição

13. Fragmentos - Juarez Filgueras de Góis

14. Gênero em questão - (Org) Antonio de Pádua Dias da Silva

15. Jogos eletrônicos - Eliane de M. Silva; Filomena M. G. da S. C Moita; e Robson Pequeno de Souza

16. Nascido do Fogo, Filho da Paz - Ket Jeffson Vasconcelos Leitão

17. Política Tributária e Justiça Social - Alexandre Henrique Salema Ferreira

18. Revista Sócio-Poética - Departamento de Letras da UEPB

19. O Sábio e a Floresta - Moacir Werneck de Castro

20. Universidade e o fazer poético em prosa e poesia - (Orgs) Fabíola Nóbrega; Marcelle V. Carvalho; e Tatiana Fernandes Sant'ana

21. Sustentabilidade - um enfoque sistêmico - (Orgs) Waleska S. Lira; Helio de L. Lira; Maria José dos Santos; e Lincon Eloy de Araújo

22. Bioquímica clínica - uma abordagem geral - Sandra Reis Farias

23. Mortalidade Geral - Epidemologia - Anthonyanny A. Silva Lima; Maria J. Cariri Benigna

24. Estudos Filológicos: Literatura - Cultura - Marinalva Freire da Silva

25. Dicionário de termos relativos a gestão de pessoas - Maria Dora Ruiz Temoche

26. Práticas de Políticas Públicas - (Orgs) Marcelo A. Pereira; Maria da G. A. Pereira; Sandra. M. A de S. Celestino; Sueli Ramos de R. M. Cavalcanti; e Wíliam A. de Lacerda

27. Saúde Humana - (Org) Inácia Sátiro Xavier de França

28. O Segredo de Pergamo - Ket Jeffson Vasconcelos Leitão

29. A queda do meteorito - Giusone Ferreira Rodrigues

30. Trajetória empreendedora: estudo de casos numa realidade local e global - (Org) Vera Lúcia Barreto Motta

31. Identidades de gênero e práticas discursivas - (Org) Antonio de Pádua Dias da Silva

32. O lugar da Educação Física - Maria José de Fígueirêdo Gomes

33. O papel político dos fóruns de educação de jovens e adultos - Eduardo Jorge Lopes da Silva

34. Pesquisa histórica - resumo de monografias - (Orgs) Luíra Freire Monteiro; e Flávio Carreiro de Santana

35. Anos de luta - Waldir Porfírio

36. Mulher e violência: histórias do corpo negado - Lígia Pereira dos Santos 
37. Agricultura orgânica - José Geraldo R. dos Santos; e Emmanuelly Calina X. R. Santos

38. Sobre o diálogo: introdução a uma leitura filosófica de - Julio Cesar Kestering

39. Novos cenários da Administração - (Org) maria Dora Ruiz Temoche

40. O despertar da cultura - (Org) Marinalva Freire da Silva

41. Manual básico de Radiologia Odontológica - Maria de Fátima Cavalcanti Rodrigues

42. Formas de sociabilidade e instauração da alteridade - Inácia S. Xavier de França; Lorita M. Freitag Paghuca

43. Paremiologia nordestina - Fontes Ibiapina

44. Resistência indígena no Piauí colonial 1718 - 1774 - João Renor F. de Carvalho

45. Planejando o (des)envolvimento local - Roberto Alves de Araújo; e Ana Siqueira de Araújo

46. Deuses em poéticas: estudos de Literatura e Teologia - (Orgs) Salma Farraz; Antonio Magalhães; Eli Brandão; Waldecy Tenório; Douglas Conceição

47. Campina Grande em debate - (Org) Roberto Véras de Oliveira

48. História do Direito e da violência: recortes de uma abordagem interdisciplinar - Marcelo Alves Pereira Eufrásio

49. Contos jurídicos: normas de sobredireito da Lei de Introdução ao Código Civil - Ket Jeffson Vasconcelos Leitão

50. A Bacia do Rio Gramame: Biodiversidade, uso e conservação - (Orgs) José Etam de Lucena Barbosa; e Takako Watanabe; e R. José da Paz

51. Ser criança - repensando o lugar da criança na educação infantil - (Orgs) Glória M. de Souza Melo; Soraya. M. de A. Brandão; e Marinalva. da Silva Mota

52. Estudos Sociais da Ciência e Tecnologia - (Org) Renato Dagnino

53. De portas abertas para o lazer - (Orgs) Elaine Melo de B. Costa Lemos; Eduardo Ribeiro Dantas; e Cheng Hzin Nery Chão

54. Gênero e práticas culturais - (Orgss) Charliton J. dos Santos Machado; Idalina M. F. Lima Santiago; e Maria L. da Silva Nunes

55. Da resistência ao poder - o (P)MDB na Paraíba (1965 / 1999) - José Otávio de Arruda Mello

56. Políticas públicas e desenvolvimento regional - (Orgs) Carlos. A. Máximo Pimenta; Cecília Pescatore Alves

57. Histórias vividas e contadas no Bar do Brito - (Orgs) A. C. Barbosa de Souza; Antonio Guedes Rangel Junior; Clara M. Araújo Pinto; e Sonia Maria A. de Oliveira Brito

58. De memória e de identidade - (Orgs) Antonia M. M. da Slva; Francisco Paulo da Silva; Ivanaldo Oliveira dos Santos; e Maria Edileuza da Costa

59. A luz que não se apaga - Rômulo de Araújo Lima

60. Cálculo avançado - (Orgs) Aldo Trajano Louredo; e Alexandro M. de Oliveira; e Osmundo Alves Lima

61. Fisioterapia na gravidez - (Org) Maria do Socorro B. e Silva

62. Educação Universitária - Pedro Bergamo

63. Amora - Fidélia Cassandra

64. Educação em questão - recortando temas e tecendo ideias - (Pedro Lúcio Barboza)

65. Ciço de Luzia - Efigênio Moura

66. Zila Mamede - trajetórias literárias e educativas - Charliton José dos Santos Machado

67. A voz da infância e outras vozes - Calos Azevedo

68. A Educação da Mulher em Lima Barreto - (Jomar Ricardo da Silva)

69. Porta aberta à poesia popular - Almira Araújo Cruz Soares

70. Mulheres representadas na literatura de autoria feminina - Antonio de Pádua Dias da Silva

71. Residências terapêuticas - (Orgs) Maria de Fátima de A. Silveira e Hudson Píres de O. Santos Júnior

72. A nuvem de hoje - Braulio Taveres

73. Tecnologias digitais na educação - (Orgs) Robson Pequeno de Sousa; Filomena M. C. da S. C. Moita; e Ana Beatriz Gomes Carvalho. 
74. A representação da sogra na obra de Leandro Gomes de Barros - José Itamar Sales da Silva

75. Viagem aos 80 anos da Revolta de Princesa - Janduí Dantas

76. Cidadania glocal, identidade nordestina - José Marques de Melo

77. Uma nova ciência para um novo senso comum - Marcelo Germano Gomes

78. A feira - o trovador encantado - Maria de Lourdes Nunes Ramalho

79. Nordeste como inventiva simbólica - Geralda Medeiros Nóbrega

80. Era uma vez diferente - Aline Pereira

81. Colecionismo, práticas de campo e representações - Maria Margaret Lopes e Alda Heizer.

82. Ensaios de Antropologia da Política - Elizabeth Christina de Andrade Lima

83. A Bela Acordada - Lígia Pereira dos Santos

84. Eu macharei na tua luta - a vida de ELISABETH TEIXEIRA - (Orgs) Lourdes M. Bandeira; Neide Miele; Rosa M. G. Silveira

85. Apropriação Social da Ciência e da Tecnologia - (Orgs) Maria C. P. I. Hayashi; Cidoval M. de Sousa; e Danilo Rotrberg

86. Midiatização da Ciência - cenários, desafios, possibilidades - (Org) Antonio Fausto Neto

87. Psicologia da Saúde - teoria, intervenção e pesquisa - (Org) Railda Fernandes Alves

88. As periércias de um caçador de ETs - Jorge Dellane da Silva Brito

89. Becquerel e a descoberta da radioatividade - Roberto de Andrade Martins

90. Mpb de A a Z (2 ediçâo) - Ricardo Anísio

91. ECO - Juarez Filgueras de Góis

92. As três verdades de Deus - Janduí Dantas

93. Sabedoria de cabôco - José Alves Sobrinho

94. Agenda Ambiental - gestão socioambiental - (Org) Antônio Augusto Pereira de Sousa; Djane de Fátima Oliveira; Givanildo Gonçalves de Farias; e Mercília Tavares Jordão

95. Etnografia e Educação - conceitos e usos - Carmen Lúcia Guimarães de Mattos; e Paula Almeida de Castro

96. Orgulho de ser caririzeiro - Victor Paulo Sampaio

97. Genealogia do Direito à Saúde - Marcone do Ó Catão

98. Antonio Carlos Nóbrega em acordes e textos armoriais - Luís Adriano Mendes Costa

99. Identidades \& sensibilidade - o cinema como espaço de leituras - (Org) Iranilson Buriti

100. Dom José Maria Pires - Uma voz fiel à mudança social - (Org) Sampaio Geraldo Lopes Ribeiro

101. Paisagens Híbridas - Fontes e escrituras da História - (Org) Juciene Ricarte Apolinário

102. Cenários históricos e educativos - Sertão, questão indígena e espaço de saber - (Org) Juciene Ricarte Apolinário 
Sobre o livro

Impressão Gráfica Universitária da UEPB

Formato $16 \times 23 \mathrm{~cm}$

Mancha Gráfica $\quad 11,5$ x $18,5 \mathrm{~cm}$

Tipologias utilizadas Bembo Std 11,5/14

Papel Apergaminhado $75 \mathrm{~g} / \mathrm{m}^{2}$ (miolo) e Cartão Supremo $250 \mathrm{~g} / \mathrm{m}^{2}$ (capa) 